\title{
Pulmonary artery sling in a symptomatic newborn
}

Onur Işık ${ }^{1}$, Muhammet Akyuz ${ }^{1}$, and Ilker Mercan ${ }^{1}$

${ }^{1}$ Izmir Tepecik Training and Research Hospital

April 28, 2020

\begin{abstract}
Pulmonary arterial sling is a relatively rare congenital anomaly in which left pulmonary artery (LPA) branch originates abnormally from the RPA, eventually resulting with respiratory symptoms, due to airway obstruction. In this report, we present a PAS in a neonate who showed progressive respiratory distress in the second week following delivery. At 25 days of age, the patient underwent total surgical correction of the anomaly, during which left pulmonary artery reimplantation to main PA without the use of cardiopulmonary bypass was employed. Following an uneventful recovery, the patient was discharged eight days after surgery.
\end{abstract}

\section{Hosted file}

PA sling.doc available at https://authorea.com/users/309401/articles/440893-pulmonary-arterysling-in-a-symptomatic-newborn
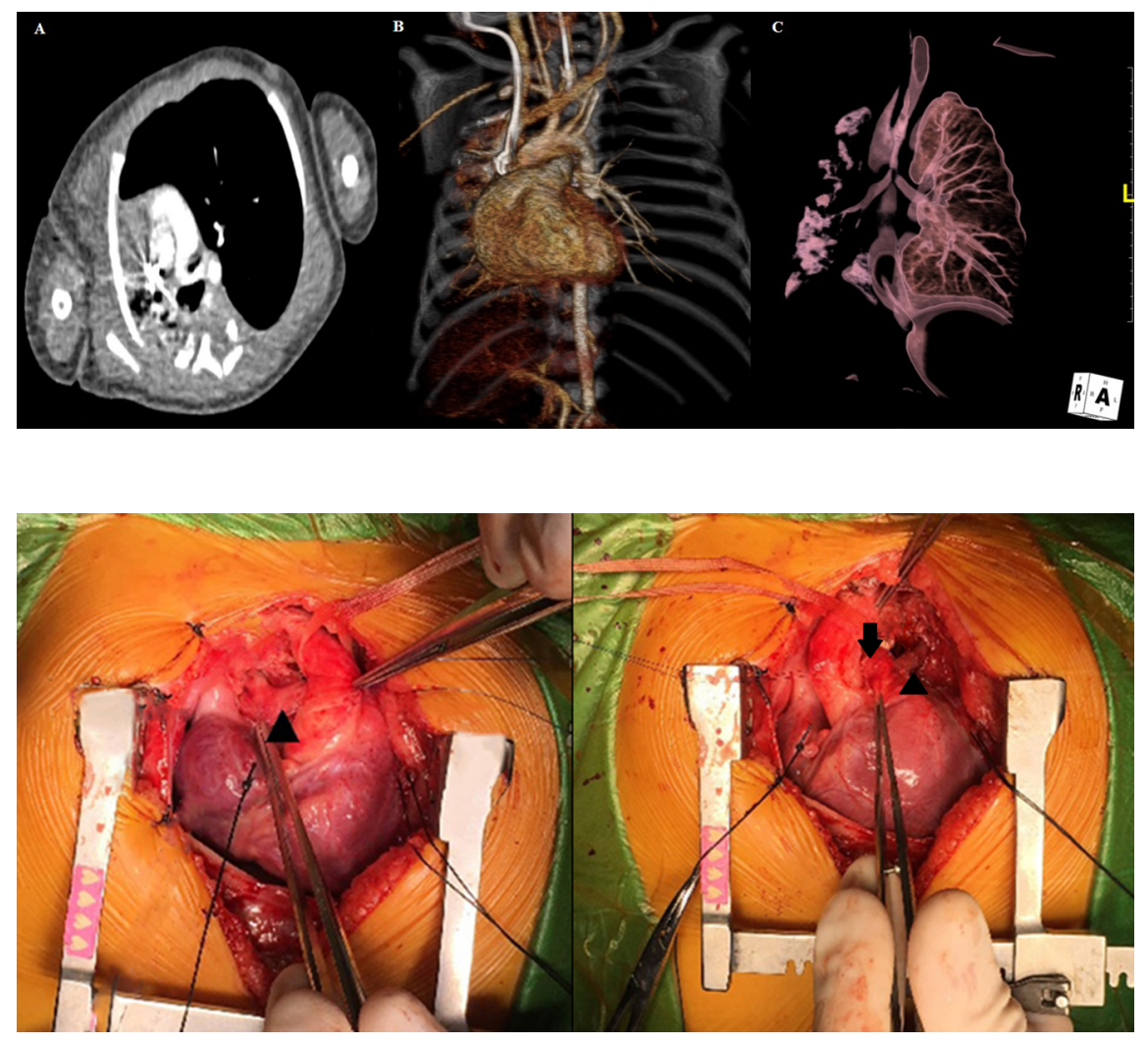


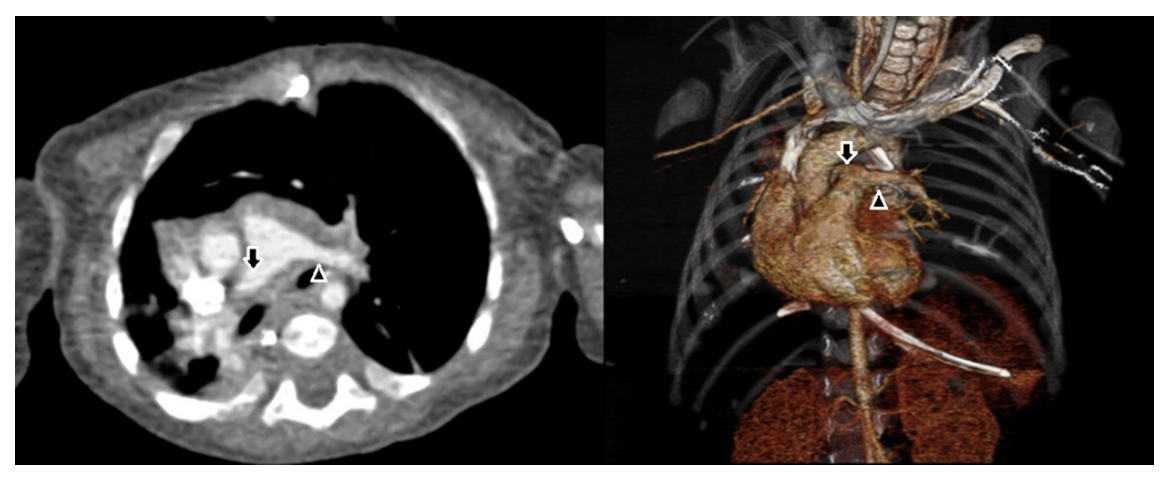

